\title{
Comparative Analysis of Serum Heavy Metals as Aluminum and Lead Level in Dialysis Patients, Pre and post Dialysis
}

\author{
Atieh Makhlough ${ }^{1 *}$, Mohammad Shokrzadeh ${ }^{2}$, Maryam Shaliji M ${ }^{3}$, Siavash Abedi ${ }^{4}$ \\ ${ }^{1}$ Molecular and cell Biology Research Center, Hemoglobinopathy Institute, Department of Internal Medicine, Nephrology Ward, Imam \\ Khomeini Hospital, Mazandaran University of Medical Sciences, Sari, Iran. \\ ${ }^{2}$ Pharmacutical Research Center, Department of Toxicology and Pharmacology, Faculty of Pharmacy, Mazandaran University of Medical \\ Science, Sari, Iran \\ ${ }^{3}$ General Physician in Mazandaran University of Medical Sciences, Sari, Iran. \\ ${ }^{4}$ Department of Internal Medicine, Pulmonary Ward, Imam Khomeini Hospital, Mazandaran University of Medical Sciences, Sari, Iran.
}

Received: 15 Feb 2014

Revised : 20 Mar 2014

Accepted: 10 Apr 2014

Corresponding Authors: Mohammad Shokrzadeh

Pharmacutical Research Center, Department of Toxicology and Pharmacology, Faculty of Pharmacy, Mazandaran University of Medical

Science, Sari, Iran

Phone: +98-9111263448

E-mail:mslamuk@yahoo.com

\begin{abstract}
Background: Accumulation or deficiency of trace elements can occur in hemodialysis patients and it increases risk of cardiovascular or other organs disorders. Special ions levels such as sodium and bicarbonate in dialysis fluid are accurately regulated but the remaining elements are not regularly measured. Aluminum and lead belong to the biologic performance free heavy metals .They also has a tendency to accumulate in hemodialysis patients. This study aims to compare serum $\mathrm{Al}$ and lead levels in hemodialysis patients before and after dialysis during 6 months period.

Materials and Methods: This comparative longitudinal research has been a comparative long- itudinal research conducted to 86 hemodialysis patients in Imam Khomeini and Fatima Zahra in Sari. Sampling was done on patients for three times (two times before dialysis with 6 months interval and one time after dialysis in the sixth month). It has been measured by spectrophotometer method. In order to compare the metal mean and standard deviation, Anova analysis method and also evaluating intra group difference with paired test has been used.

Results: In the 100 hemodialysis patients, the mean age and duration of hemodialysis were $57.0 \pm 7.3$ years and $15.28 \pm 5.73$ months, respectively. Al level in patient's serum was $30.7 \pm 6.2$ and $37.5 \pm 6.8 \mathrm{mg} / \mathrm{dl}$ before and after dialysis, respectively. The post-dialysis Al level became statistically significant $(\mathrm{p}<0.05)$. There was no significant difference between pre dialysis Al concentrations during 6 months interval. We weren't finding significant difference in lead level between the three samples taken.

Conclusion: Trace elements status in chronic kidney diseases patients is influenced by a renal function residual, size and dialyzer membrane surface. The water nature also is used for dialysis fluid preparation and composition. Trace elements in ESRD patients differed from healthy individuals. So this issue requires accurate studies on trace elements clinical aspects in ESRD patients.
\end{abstract}

Keywords: Hemodialysis; Aluminum; Lead

Please cite this article as: Makhlough A, Shokrzadeh M, Shaliji M, Abedi S. Comparative Analysis of Serum Heavy Metals as Aluminum and Lead Level in Dialysis Patients, Pre and post Dialysis. Res Mol Med. 2014; 2 (2): 34-39

\section{Introduction}

End stage renal Disease (ESRD) refers to the $5^{\text {th }}$ stage of chronic kidney diseases (CKD) that glomerular filtration rate (GFR) reduces to lower than $15 \mathrm{ml} /$ $\min / 1 / 73 \mathrm{~m}^{2}$ and toxins accumulate in body so that electrolyte homeostasis. Mortality and morbidity increase in them and they need to using of renal replacement treatment (1). Renal replacement treatment in ESRD include hemodialysis, peritoneal 
dialysis and renal transplant that hemodialysis is the most common route in the Word (1-2).

The accumulation of some Trace elements in hemodialysis will affect the body and may increased significant clinical complication for cardiovascular, bone, immune system and anemia. Decrease and increase Trace elements can cause important clinical complications. The degree of a renal failure and the route of the renal replacement therapy are the most important factor in TES concentration. In contrast, uremic toxins can change the uptake and toxicity of TES significantly (3).

The uptake of Aluminum is done by intestines, and the most of it is excreted through feces as unabsorbed.

Little amount of AL is absorbed and it's quickly secreted inside urine and some remains in skeletal system. At the first $\mathrm{Al}$ is accumulated in bone and subsequent in brain and kidney (4-6).

Table 1. Serum levels of aluminum (AL) and lead based on dialysis adequacy in three sampling stages.

\begin{tabular}{|c|c|c|c|}
\hline \multirow[t]{2}{*}{ Metal } & \multirow{2}{*}{ Sampling time } & \multicolumn{2}{|c|}{ Dialysis adequacy } \\
\hline & & $<1.2 \mathrm{KT} / \mathrm{V}$ & $>1.2 \mathrm{KT} / \mathrm{V}$ \\
\hline \multirow{3}{*}{ Aluminum (mg/dl) } & First time & $28.3 \pm 7$ & $27.8 \pm 7.1$ \\
\hline & Six month pre-dialysis & $30.6 \pm 5.9$ & $30.8 \pm 7.2$ \\
\hline & Six month post - dialysis & $37.2 \pm 6.8$ & $38.4 \pm 6.6$ \\
\hline \multirow{3}{*}{ Lead (mg/dl) } & First time & $6.2 \pm 1.9$ & $6.1 \pm 2.1$ \\
\hline & Six month pre-dialysis & $6.6 \pm 2$ & $6.1 \pm 2$ \\
\hline & Six month post- dialysis & $7 \pm 1.9$ & $7.1 \pm 2.3$ \\
\hline
\end{tabular}

Special factors such as uremic syndrome, diabetes, secondary hyperparathyroidism, Alzheimer's disease and Down's syndrome would change AL uptake and also residue in bone. Individuals like ESRD patients in case of suffering from Iron deficiency are at higher risk to $\mathrm{AL}$ poisoning (7). Besides this protective performance, digestive barrier in ESRD patients is less effective than healthy people because it is taking Aluminum based medicine in such patients (5).

Some Trace elements can decrease renal function such as Lead, cadmium and copper (7). Lead is a metal without biological function. The body cannot use it but can absorb and store. Lead has an accumulative effect and its poisoning can be made even in a little amount. Most $\mathrm{Pb}$ in body turns to residue in bone (8). Lead affects many organs and induces encephalopathy, anemia, peripheral neuropathy, hypertension, digestive dysfunctions, fatigue, renal failure and gout (9).

Behavioral disorder involves illusion and the central neural system disorders are also seen when they exposed to acute and server lead levels with chronic encounter with a little lead levels and peripheral neuropathy symptoms. (10). Epidemiologic studies that show blood lead level is related to cardiovascular causes and mortality due to malignancy. It can result in hypertension and also accelerate kidney function disorder which is related to the age in humans (1114). The recent studies regarding the relation between environmental exposures to lead and a progressive renal failure have demonstrated that using chelating substances causes to the prevent renal failure advancing in patients with chronic kidney impairment (15). Studies on serum lead level show that it bringsabout mortality risk increase in a group of diabeticpatients on chronic blood and peritoneal dialysis (10).

The critical TES presence which plays key role in various biological systems sets forth this theory that increasing morbidity and mortality presence in dialysis patients would be is due to some TES in equilibrium that is not known yet (16).

In this study we assessed the serum levels of lead and $\mathrm{AL}$ in hemodialysis patients and evaluated serum level change after six months of dialysis. Also the impact of geographic and the environmental conditions on heavy metals level were compared before and after dialysis for 6 months period.

\section{Materials and Methods}

The conducted study has been a comparative longitudinal. 100 hemodialysis patients qualified in Imam Khomeini \& Fatima Zahra hospitals hemodialysis ward were included in Sari in 2010. All patients were agree with study enrolled in study if they did not use syrup or drugs of AL. Demographic Findings were collected by a questionnaire via experts. Then $10 \mathrm{ml}$ fasting blood was taken from every patient from peripheral blood vessels (two times before dialysis and one time after dialysis in the sixth month). The sampling was done at the first time in pre-dialysis but two samples were done in the pre- 
dialysis and post-dialysis in the sixth month. Then, samples were added to the acid-wash poly propylene tubes and samples were rapidly transferred to Imam Khomeini hospital laboratory under the sterile conditions for centrifugation and serum isolation. After centrifuging blood and isolating serum from globules, serum has been transferred into another sterile tube by sampler and stored at $20^{\circ} \mathrm{C}$. After numbering samples, they were transferred to pharmaceutical Faculty by observing the cold chain and the standard requirements. So the serum levels of these metals were measured through Atomic absorption spectrophotometer method.

\section{Intervening variables}

Drinking water: Ignoring

Membrane material \& Hemodialysis kinds:

Homologizing

Aluminum syrup or supplementary Medicine taking Background disease, age, gender, times \& length \&kind of dialysis: Recording

Table 2. Serum levels of aluminum and lead based on some affecting factors

Aluminum (mg/dl) Lead (mg/dl)

\begin{tabular}{lcc}
\hline Dialysis characterization & & \\
Twice a week & $30.3 \pm 7.8$ & $6.8 \pm 1.9$ \\
Three times a week & $27.6 \pm 6.6$ & $6.1 \pm 1.9$ \\
Gender & \\
Females & $27.2 \pm 5.5$ & $6.4 \pm 1.9$ \\
Males & $29 \pm 7.4$ & $6.1 \pm 2$ \\
Residency & \\
Rural & $28.9 \pm 5$ & $6.2 \pm 2$ \\
Urban & $27.5 \pm 7.2$ & $6 \pm 1.8$ \\
\hline
\end{tabular}

Samples preparation

All samples have been exposed to Lab setting temperature and defreeze. They were also diluted by using $10 \%$ Tritone solution in $0.1 \%$ normal Nitric Acid to 1:10 level.

The reason of using triton to such value has been to create viscosity similar to plasma in diluted serum.

Standard solution Making:

Separately, $100 \mathrm{mg}$ standard level of every metal as $\mathrm{AL}$ and $\mathrm{Pb}$ (made by German company) was dissolved in deionized and it reached to volume in $100 \mathrm{ml}$.

Belongs to the mentioned metals and considered as stock, it was separately prepared for every metal at $0.2,0.4,0.6 \& 0.8$ concentrations.

\section{Samples Analysis}

The prepared samples in the previous stage were utilized through three phases with the same machine settings for achieving the standard curves from each metals standard solution that were analyzed separately for each metal. The absorption level of every sample was gained for each metal.

The absorption related to each metal was included in the achieved calibration curve equation of the same metal and the produce was multiplied by dilution factor that was 10 in this way, the considered metal concentration was measured.

\section{Statistical Analysis}

Analyzing data in SPSS software version 15, estimating the metals mean and standard deviation by prism software, comparing the mean and standard deviation of the metals under evaluation, Anova variance analysis was applied. The paired $t$ - test was used for assess intra groups difference. The $\mathrm{P}$ Value lower than 0.05 was considered as a significant difference.

\section{Results}

One hundred patients were included in this study (54 men and 46 female) that 14 out of whom were removed through the study. The mean age and duration of hemodialysis were $57.0 \pm 7.3$ years and $15.28 \pm 5.73$ months, respectively.

About basic pre-dialysis and six months later predialysis aluminum, there was no meaningful difference; however, a significant difference was found between basic and the sixth month pre-dialysis and the sixth month post-dialysis $(\mathrm{p}<0.05)$. Lead concentrations have showed no meaningful difference between samples $(\mathrm{p}<0.05)$.

Comparing the study metals concentrations based on dialysis adequacy revealed no statistical significant differences.

Statistical analysis in terms of dialysis time's number effect per week on serum heavy metals levels in the study has indicated that there was no significant. In addition, comparison of the levels of $\mathrm{Al}$ and $\mathrm{Pb}$ among two genders was not shown any significant differences (Table 3). Residency status was not affected the serum concentrations of these two metals. In statistical comparison of the generating factor of ESRD and its effect on the study metals concentration, there was no meaningful difference.

\section{Discussion}

In this study, we showed that the serum level of AL is higher than normal level (less than 20mg) in ESRD patients but it didn't reach to toxic level via medications. The statistical analysis of pre-dialysis Al concentration during 6 months didn't reveal any 
meaningful difference. However, in comparing serum Al level before and after dialysis, a significant difference has been observed. This indicates that $\mathrm{Al}$ level has been increased due to dialysis. Many study showed that serum Aluminum level has been vividly higher than control group (13-14). In the research done by Kazi et al pre-dialysis serum Al level was higher than post-dialysis one (15) have discovered in their study that serum Al level doesn't change by dialysis.

Table 3. Serum levels of aluminum and lead Mean Based on background diseases

\begin{tabular}{lll}
\hline & Aluminum(mg/d) & Lead $(\mathbf{m g} / \mathbf{d l})$ \\
\hline Hypertension & $28.3 \pm 5.4$ & $6.5 \pm 1.7$ \\
Diabetes & $30.4 \pm 10.8$ & $6.2 \pm 2.2$ \\
Hypertension and diabetes & $27.6 \pm 6.4$ & $5.7 \pm 2$ \\
Kidney stone & $19.9 \pm 0.3$ & $4.9 \pm 1.6$ \\
Unknown & $26 \pm 7.6$ & $5.6 \pm 2.7$ \\
\hline
\end{tabular}

Prodanchuk and other authors analyzed the Trace elements such as aluminum, manganese, cobalt, nickel, copper, zinc, lead) concentration in the whole blood of 41 ESRD patients who were treated with hemodialysis and hemodiafiltration and also of 61 healthy blood donors. Levels of aluminum, vanadium, chromium, manganese, zinc, strontium, cadmium, barium and lead were significantly increased in ESRD patients. Significantly decreased levels were observed for nickel, arsenic, selenium and rubidium. Blood levels of cobalt, copper, cadmium and lead in hemodialysis patients were significantly higher compared to patients receiving hemodiafiltration (17-18).

In some studies showed $\mathrm{Al}$ level were related to hemodialysis treatment period and $\mathrm{AL}$ effects in hemoglobin synthesis. Al increase has serious complications in patients with renal impairment and now this problem is being greatly prevented by Aluminum-free phosphatic binding agent's consumption $(1,19)$. Plenty of studies on Al toxicity in hemodialysis patients have caused Aluminum accumulation in patients to be decreased extensively today (2).

Rucker showed $\mathrm{Pb}$ accumulation in hemodialysis patients has been pointed out (20) but Kazi et al pre dialysis serum $\mathrm{Pb}$ level was higher than after dialysis (21) while our findings suggest that serum $\mathrm{Pb}$ level has gone up by doing dialysis same to Devenport's study (22) but in statistical comparison there was no meaningful difference. Prodanchuk and Subha
Palaneeswar showed that the blood lead level is higher in the hemodialysis patients than general population $(19,23)$. Lead increases with impaired renal excretion in ESRD and it can stimulate bone absorption and bone disorders .In addition the environmental exposure to $\mathrm{Pb}$ can bring $\mathrm{Pb}$ rise in dialysis patients (10).

In these study heavy metals levels did not differ in male and female patients. Also time of number per week and residing in sari compared with the villages, there was no meaningful statistical difference. Besides; appropriate dialysis adequacy had no effect on serum metals level before and after dialysis. At the point of relation between backgrounds reason of renal impairment and heavy metals level, there was no meaningful statistical difference between the study groups. Trace elements physiology is highly complicated because their secretion ways are binding with protein and tissue concentrations (24). It is clear that Trace elements status in ESRD patients is different from healthy people and this issue makes the requirement of careful studies on clinical impact of Trace elements in blood and ESRD patient's tissues vivid. With respect to the findings of this research and other analogous studies, it's suggested that heavy metals levels in dialysis fluid and patient's drinking water should be analyzed and also a study on Trane elements clinical impacts should be done. In addition, performing intervention studies in terms of Trace elements supplements can be highly effective in ESRD patient's destiny.

\section{Acknowledgment}

This study was supported by grant of Mazandaran University of Medical sciences. This paper is the result of a medical degree thesis (by Dr Shaliji).

\section{References}

1. Kasper Dl, Braunwald E, Fauci AS, Hauser SL, Longo DL, Jameson JL, et al, editors. Alterations in Renal and Urinary Tract Function. $17^{\text {th }}$ ed. New York: McGraw-Hill Medical Publishing Division; 2008. P. 134-37.

2. Tonelli M, Wiebe N, Hemmelgarn B, Klarenbach S, Field C, Manns B, et al. Alberta Kidney Disease Network. Trance elements in hemodialysis patients: a systematic review and Meta - analysis. BMC Med. 2009; 19: 7-25. PMID: 19454005

3. Vanholder R, Cornelis R, Dhondt A, et al. The role of trace elements in the uremic toxicity. Nephrol Dial Transplant. 2002; 17 (2): 2-8. PMID: 11904350

4. Wills MR, Savory J. Water content of aluminum, dialysis dementia and osteomalacia. Environ Health Perspect 1995; 63: 141-147. PMID: 3908086

5. Drueke TB. Intestinal absorption of aluminium in renal failure. Nephrol Dial Transplant. 2002; 17 (2): 13-16. PMID: 1190435

6. Soderland P, Loverkar S, Weiner DE, et al. Chronic kidney 
disease which is associated with environmental toxins and exposures. Adv Chronic Kidney Dis. 2010; 17 (3): 254-64. PMID: 20439094

7. Cannata JB, Fernandez- soto I, Fernandez Menedez MJ ,et al. Role of iron metabolism in absorption and cellular uptake of aluminium. Kidney Int. 1991; 39(4):799-803. PMID: 2051739

8. Kessler M, Durand PY, Huu TC, Royer- Morot MJ, Chanliau J, Netter P, et al . Mobilization of lead from bone in end-stage renal failure patients with secondary hyperparathyroidism. Nephrol Dial Transplant. 1999; 14(11): 2731-3. PMID: 10534522

9. Pulley MT. Lead neuropathy [Internet]. Florida: Jacksonville; 1999 [Undated]. Available from: http://www.medlink.com/medlinkcontent.asp.

10. Schober SE, Mirel LB, Graaubard BI, Brody DJ, Flegal KM. Blood lead levels and from all causes, cardiovascular disease and cancer: result from the NHANES III mortality study. Environ Health Perspect. 2006; 114(10): 1538-41. PMID: 17035139

11. Menke A, Muntner P, Batuman V, Silbergeld EK, Guallar E. Blood lead below 0.48 micromol/l $(10 \mathrm{microg} / \mathrm{dl})$ and mortality among US adults. Circulation. 2006; 114(113): 1388-94. PMID: 16982939

12. Staessen JA, Lauwerys RR, Buchet JP, et al. The cadmibel study Group: Impairment of renal function with increasing blood lead concentrations in the general population. N Engl J Med. 1992; 327(3): 151-6. PMID: 1608406

13. Kim R, Rontnitzky A, Sparrow D, Weiss ST, Wager C, Hu H. A longitudinal study of low level lead exposure and impairment of renal function. The Normative Aging Study. JAMA. 1996; 275(15): 1177-81. PMID: 8609685

14. Lin JL, Lin -Tan DT, Hsu kh, Yu CC. Enviromental lead exposure and progression of chronic renal diseases in patients without diabetes. N Engl J Med. 2003; 348(4): 277-86. PMID: 12540640

15. Lin JL, Lin-Tan DT, Yen TH, et al. Blood lead levels,malnutrition, inflammation, and mortality in patients with diabetes treated by longterm hemodialysis. Am J kidney Dis. 2008; 51(1): 107-15. PMID: 18155539
16. El-Sherbeny SSA, Asmaa, Abd Allah M, Massoud W. Copper, Zinc, Selenium, Cadmium and Lead Levels in plasma of Hemodialysis Patients. Egyptian J Hosp Med. 2006; 24: 556-63.

17. Prodanchuk M, Makarov O, Pisarev E, Sheiman B, Kulyzkiy M. Disturbances of trace element metabolism in ESRD patients receiving hemodialysis and hemodiafiltration. Cent European J Urol. 2014; 66 (4): 472-6. PMID: 24757548

18. Hasanato RM. Assessment of trace elements in sera of patients undergoing renal dialysis. Saudi Med J. 2014; 35 (4): 365-70. PMID: 24749133

19. Filler G, Felder S. Trace elements in dialysis. Pediatr Nephrol. 2013.

20. Rucker D, Thadhani R, Tonelli M. Trace element status in hemodialysis patients. Semin dial. 2010; 23 (4): 389-95. PMID: 20557491

21. Kazi TG, Jalbani N, Kazi N, Jamali MK, Arain MB, Afridi HI, et al. Evaluation of toxic metals in blood and urine samples of chronic renal failure patients, before and after dialysis. Ren Fail. 2008; 30 (7): 737-45. PMID: 18704823

22. Devenport A, Murcutt G, Whiting S. Cross - sectional audit of blood lead levels in regular outpatient haemodialysis patients dialyzing in north London. Nephrology (Carlton) 2009; 14 (5): 476-81. PMID: 19674316

23. M SP, Rajan PM, Santhi S, Jothimalar. Blood Lead in EndStage Renal Disease (ESRD) Patients who were on Maintainence Haemodialysis, J Clin Diagn Res. 2012; 6 (10): 1633-5. PMID: 23373016

24. Diskin CJ. An understanding of trace metal physiology as an aid to interpretation of clearance studies by artificial organs. Nephrol Dial Transplant. 2007; 23 (4): 1462. PMID: 18029373 